\title{
Computer Simulation and Animation in Engineering Mechanics: A Critical Review and Analysis
}

\section{Oai "Andy" Ha, Utah State University}

Oai Ha is currently a Ph.D. student in the Department of Engineering Education in the College of Engineering at Utah State University. He works as a graduate research assistant on a research project that focuses on studying the effect of computer simulation and animation on student learning in engineering dynamics. He received his B.S. in Mechanical Engineering from the University of Technology, Hochiminh City, Vietnam, and his M.S. in Mechanical Engineering from California Polytechnic State University, San Luis Obispo. Before joining USU, he had eleven years of working experience in engineering and construction. His research interests include computer simulation and animation, numerical modeling, cognition and metacognition, and multimedia learning.

\section{Prof. Ning Fang, Utah State University}

Ning Fang is an Associate Professor in the College of Engineering at Utah State University. He has taught a variety of engineering courses such as engineering dynamics, metal machining, and design for manufacturing. His areas of interest include computer-assisted instructional technology, curricular reform in engineering education, the modeling and optimization of manufacturing processes, and lean product design. He earned his Ph.D., M.S., and B.S. degrees in mechanical engineering and is the author of more than 60 technical papers published in refereed international journals and conference proceedings. He is a Senior Member of the Society for Manufacturing Engineering and a member of the American Society of Mechanical Engineers. He is also a member of the American Society for Engineering Education and a member of the American Educational Research Association. 


\title{
Computer Simulation and Animation in Engineering Mechanics: A Critical Review and Analysis
}

\begin{abstract}
Nearly all students in mechanical, aerospace, civil, environmental, and biomedical engineering majors are required to take engineering mechanics courses. These courses cover a broad spectrum of foundational engineering concepts and require students to have solid spatial visualization skills. This paper presents a critical literature review and analysis of the behavioral and technical constructs of published studies on the development and assessment of web-based computer simulation and animation (CSA) modules and programs used in engineering mechanics education, particularly in engineering statics and dynamics. Popular databases, such as EBSCOhost, ERIC, Web of Knowledge, and annual ASEE conference proceedings, were employed to identify relevant papers.
\end{abstract}

This paper presents definitions of the terms "computer simulation" and "computer animation." Three important aspects of CSA modules and programs are described in great detail, including 1) web-based CSA modules and programs developed for engineering mechanics; 2) cognitive aspects of interactive learning with web-based CSA modules and programs; and 3) development of interactive web-based CSA modules and programs. Based on relevant studies published in the literature, this paper analyzes nine characteristics among published studies, including 1) commonly-reported student learning outcomes; 2) sample sizes; 3) area of study; 4) authoring tools, development software, and proprietary software on the client side; 5) mathematic equation presentation; 6) user control; 7) other media besides animation; 8) experimental design; and 9) data collection methods.

The critical literature review and analysis preformed in the present study resulted in a series of research findings. For example, it was found that many existing CSA modules and programs developed for engineering mechanics were not designed in a way in which cognitive principles associated with Cognitive Learning Theory could be adequately addressed in order to reduce cognitive load and therefore enhance student learning more effectively. Most assessment studies reported in the literature relied heavily on students' responses to self-reported questionnaire surveys, which might not truly reflect student learning gains. Many assessment studies were performed with neither a control group nor random assignment of student participants, omissions which presented a significant threat to their validity. Based on our research findings descried in this paper, we suggest that particular attention be paid to control students' cognitive load at an appropriate level when designing and implementing CSA modules and programs in order to maximize student learning outcomes.

\section{Introduction}

In learning many engineering subjects, students must develop skills to visualize the motion of objects over space and time. With advances in computer technology and communication networks, more and more engineering educators have employed web-based computer simulation and animation (CSA) modules to enhance student visualization and understanding of complex 
concepts and phenomena ${ }^{1}$. There is also a growing trend in industry to use online CSA in a variety of professional training programs for employees. Typically, the learning objectives of these professional training programs focus more on advanced topics that employees need to learn in order to carry out his/her work, rather than on broad foundational topics taught in traditional undergraduate classrooms.

CSA modules are employed in undergraduate courses in the broad area of engineering mechanics, such as statics, dynamics, and strength of materials (or alternatively called mechanics of materials). These courses are high-enrollment, high-impact, and core courses that nearly all students in mechanical, aerospace, civil, environmental, and biomedical engineering majors are required to take. For example, many universities and colleges offer engineering mechanics either as an integrated course that covers both statics and dynamics, or as two separate courses with one course focusing on statics and the other subsequent course focusing on dynamics.

Engineering mechanics covers a broad spectrum of foundational engineering concepts and requires students to have strong spatial visualization skills and abstract thinking and reasoning skills. A wide variety of CSA modules (also called CSA programs in the literature) have been developed to enhance student learning in dynamics (such as by Cornwell ${ }^{2}$, Fong ${ }^{3}$, and Stanley ${ }^{4}$, ${ }^{5}$ ), statics (such as by Hubing et al. ${ }^{6}$, and Sidhu, Ramesh, \& Selvanathan ${ }^{7}$ ), both dynamics and statics (such as by Deliktas ${ }^{8}$ and William II et al. ${ }^{9}$ ), and strength of materials (such as by Rhymer, Jensen, \& Bowe ${ }^{10}$ ). The reported benefits of these CSA modules and programs on students vary among different studies. In most studies, students reported that CSA modules and programs enhanced their spatial visualization skills, improved their understanding of course materials, and helped them gain interactive and independent learning experiences. However, in other studies, student participants expressed high dissatisfaction with some features of CSA modules and programs, such as user interactivities and increased time taken to learn ${ }^{3}$. The true benefits of CSA in engineering mechanics, however, remain debatable due to the lack of rigorous assessments requiring a control group and randomly assigned student participants.

On the other hand, research findings from cognitive psychology as well as from learning and instruction sciences suggest that animation does not have significant advantages over still pictures $^{11,12,13}$. It has been argued that in many situations, animation increases cognitive load and distracts learners ${ }^{14}$. Even in abstract domains of knowledge, like computer algorithms or physics concepts, animation does not prove to be superior over a traditional textbook with static graphics. However, animation is beneficial over static graphics in cases in which users are given controls over the pace of animation and the contents presented to them, and thus have interactivity with the animated graphics ${ }^{13,15}$. Some researchers have used the Cognitive Load Theory to explain the learning process with animation, and suggested principles for the design and development of computer animation programs to maximize student learning outcomes.

The overall goal of the extensive literature review presented in this paper is to investigate the behavioral and technical constructs of published research studies on web-based CSA modules and programs in statics and dynamics. CSA modules developed for other engineering mechanics courses, such as strength of materials, are not covered in this paper and will be addressed in detail in future work. Popular databases, such as EBSCOhost, ERIC, Web of Knowledge, and annual ASEE conference proceedings, were employed to identify pertinent papers reporting the 
development and assessment of web-based CSA in the engineering mechanics classroom. Four relevant papers were initially identified by using a combination of the following keywords/key phrases: engineering mechanics, animation, simulation, and web based. Seven additional papers were subsequently identified by searching the references listed in the initial four articles as well as by searching other secondary sources. Papers that addressed spatial visualization and interactive learning in statics and dynamics were also examined. Papers published before 1996 or which did not involve web-based learning activities were excluded from the present study.

The remaining parts of this paper contain the following contents. First, the definitions of computer simulation and computer animation are provided. Then, three important aspects of CSA modules and programs are described in great detail, including: 1) web-based CSA modules and programs developed for engineering mechanics; 2) cognitive aspects of interactive learning with web-based CSA modules and programs; and 3) the development of interactive web-based CSA modules and programs. Next, the study characteristics of 11 published papers on the development and assessment of CSA modules and programs are analyzed, with summary reports provided in Appendices A and B. Suggestions and conclusions are made at the end of this paper.

\section{Definitions of Computer Simulation and Computer Animation}

Although computer animation and simulation have been used to help students visualize a variety of phenomena, the terms of "computer simulation" and "computer animation" are not explicitly well defined in most of the studies that are examined in this paper. Only a few studies included definitions of these two terms. According to Larvive 16, "animation" is a form of cartoon used to help one visualize a difficult concept, in place of a description of the concept in words; and "simulation" is a program that accepts inputs, and simulates experimentations via computer calculation. Homer and Hayward ${ }^{17}$ defined animation as a dynamic visualization that displays the process of change over time, and defined simulation as an interactive dynamic visualization which permits learners to control and manipulate the dynamic presentation of information. In comparison to animation, simulation is usually more computationally expensive because it is based on a mathematical model that simulates a scientific processes. Rieber et al. ${ }^{18}$ noted that computer simulation not only provides a dynamic visualization, but also processes the underlying mathematical calculation in a complex system and helps learners focus on conceptual understanding of the system ${ }^{18}$. The view of computer animation as a series of frames put in sequence is reflected in the following definition by Betrancourt \&Tversky ${ }^{12}$ :

"Computer animation refers to any application that generates a series of frames, so that each frame appears as an alteration of the previous one, and in which the sequence of frames is determined either by the designer or the user."

According to the above definition, if the frames contain texts, pictures, and 2D or 3D graphics in different sizes, shapes, positions, and colors, computer animation can consist of text animation, color animation, graphic animation, or a combination of these animations.

Simulation and animation are two separate steps in commercial multi-physics simulation software packages (such as ANSYS and COMSOL) and in multi-body system simulation software (such as MSC Adams). During the simulation step, computers actually do calculations 
and store output data in their internal memory or files. During the animation step, computers read the output data, render it into graphical images, and present simulation results on the computer screen. For example, in an ANSYS computational fluid dynamics simulation, the computer program discretizes the spatial domain and solves governing equations for mass, momentum, and energy for each finite volume. In a multi-body computer program, computers calculate position, velocity, acceleration, and force for all parts in the system, and determine how forces are transferred from one part to another. In order to meet market demands for different postprocessing requirements, the output data generated from simulation steps in these commercial simulation programs can be written into a wide array of file formats for purposes of visualization and evaluation. Plots, tables, images, and animations are some typical approaches to reporting simulation results.

In summary, computer simulation is considered to be scientifically-based and has been used in science and engineering to simulate real-world physical processes and phenomena without building a real-world physical model, the latter of which can be complicated, hazardous, expensive, and time consuming in many situations. However, animation is considered a dynamic presentation of graphics, texts, and colors that are put in sequential frames to obtain certain visual effects (for aesthetics, appeal, or viewer's attention gaining, etc.). Simulation is not necessarily connected to animation, and vice versa. They do not necessarily take place at the same time or on the same computer, as in the case of simulation using server cluster technology ${ }^{19}$. In many fields, animation may involve mathematic calculations that are based on computational methods, as in physics-based animation; therefore, the discrepancy between animation and simulation sometimes becomes blurred. Usually, engineering educators develop CSA modules and programs for their own courses. For the learning modules and programs that involve only animation, no mathematical models are used to build the animation. For those that involve both simulation and animation, the output data from simulation are fed directly into animation as if both steps take place simultaneously. Nevertheless, the terms of simulation and animation are actually used interchangeably by many engineering educators.

\section{Web-Based CSA Modules and Programs Developed for Engineering Mechanics}

\section{Spatial visualization skills}

In some literature, visualization skills are referred to as spatial visualization skills, or visualspatial skills, which encompass a student's skills to generate, recall, and manipulate 2D or 3D objects within his or her mind. Mohler ${ }^{20}$ emphasized that many researchers in engineering disciplines acknowledge the importance of spatial visualization skills. As a student advances in his or her program of study, spatial visualization skills become increasingly important. Sorby, Drummer, \& Hungwe ${ }^{21}$ noted that spatial visualization skills and mental rotation skills are especially important for technical professions, such as engineering. From a research study among technology education teachers, Brown ${ }^{22}$ found that chunking-related techniques, such as visualization and graphic organizers, were important in teaching and learning. Eighty percent (n $=30$ ) of technology education teachers rated visualization skills as essential or very important. The remaining $20 \%$ rated visualization skills as important or somewhat important. 
Not all people are born with high visualization skills. Findings from many research studies conclude that learners' visualization skills can be significantly improved through effective training, particularly for those who performed poorly in a spatial skill test ${ }^{23}$. Cornwell ${ }^{2}$ found that a dynamic simulation program, called Working Model, helped students visualize the motion of an object. He argued that the simulation program was beneficial for students, helping them to observe the complex motions of rigid body systems. For example, students could observe the change in acceleration at various points on a rotating rigid body. Computer simulation and animation modules provide students with visual support, so students can develop mental models to understand the behavior of a complex physical system in the real world. As Greeno, Collin, \& Resnik ${ }^{24}$ pointed out, "these simulations allow students to learn important knowledge and skills in contexts that they could never participate in naturally, to see features that are invisible in real environments (e.g., the center of mass, the insides of pipes), to control variables that are not possible to control in the real world, and to see these in action, unlike static text figures."

\section{CSA modules' benefits in engineering mechanics education}

Students must have strong visualization skills in order to understand kinematic concepts in an engineering dynamics problem. For example, the general planar motion of a rigid body can be described as a combination of translation and rotation. To determine velocities and accelerations at various points on a rigid body that undergoes a general planar motion, students need to perform relative motion analysis, a process that requires spatial visualization skills. In relative motion analysis, one set of coordinates is fixed and measures absolute displacements, either rotation or translation, of a rigid body. The other set of coordinates is attached to the selected "base point" on a rigid body and measures relative displacements, either rotation or translation, of other points on the same rigid body.

Take Figure 1, bar AB in a four-bar linkage system, as a specific example ${ }^{25}$. In a traditional instructional material, such as a textbook ${ }^{25}$, the general planar motion of bar AB in Fig. 1 is divided into two phases and is depicted by two static illustration figures. First, the entire bar AB translates by an amount $d r$ so that A, called the "base point," moves to the final position, and point B move to B'. Then the bar AB rotates about A by an angle of $d \theta$ so that B' undergoes a relative displacement $d r_{B / A}$ and moves to its final position $\mathrm{B}^{25}$
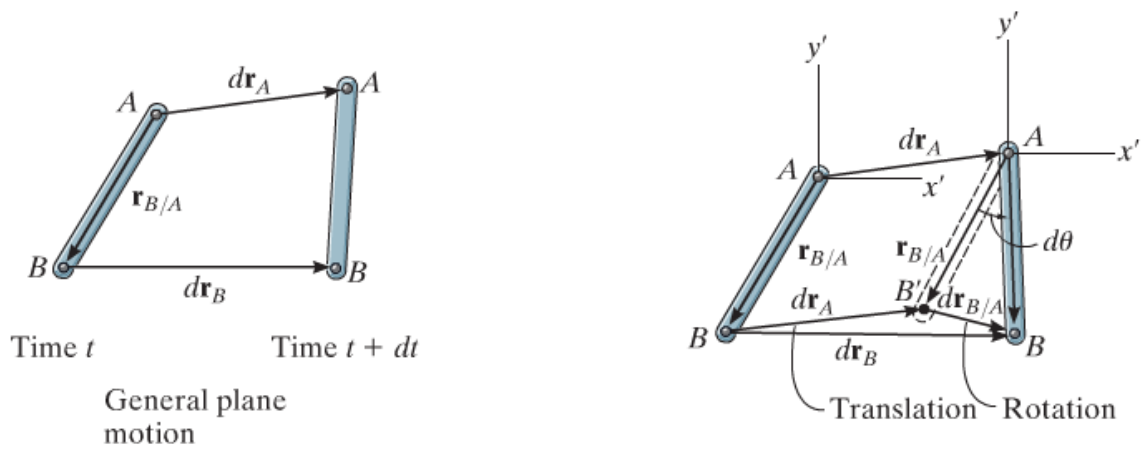

Figure 1. Relative-motion analysis ${ }^{25}$. 
However, in reality, the bar $\mathrm{AB}$ neither translates and then rotates, nor, alternatively, rotates and then translates as described in the textbook ${ }^{25}$. It rotates and translates simultaneously. Animation offers potential advantages over static graphics by explicitly depicting dynamic changes in the bar's position over time, rather than requiring the learner to "mentally" figure out those changes. In addition, animation helps learners visualize the motion and relationship among component parts of complex systems or structures ${ }^{8,19,26}$. For example, compared to static graphics, animation helps students better understand the concept of instantaneous center in a general planar motion of a rigid body ${ }^{27}$.

Animation can represent the relationships between variables more explicitly than can a mathematical equation. With animation on a computer screen, students can clearly observe how vector variables change in magnitude and direction. For example, in Stanley's studies ${ }^{5,28}$, an animated motorcycle traveled along a defined path with a constant tangential acceleration. The students were asked, "Why does the acceleration vector change direction and magnitude as it moves along the trajectory?" Mathematically, the motorcycle's normal acceleration is proportional to its velocity and inversely proportional to the radius of the trajectory curve. From the mathematic equations alone, not many students could figure out the answer to this question. However, with the computer animation program, eighty-five percent of the students answered correctly $^{5,28}$. Figure 2 shows screenshots of the animated motorcycle module and it inputs and outputs.
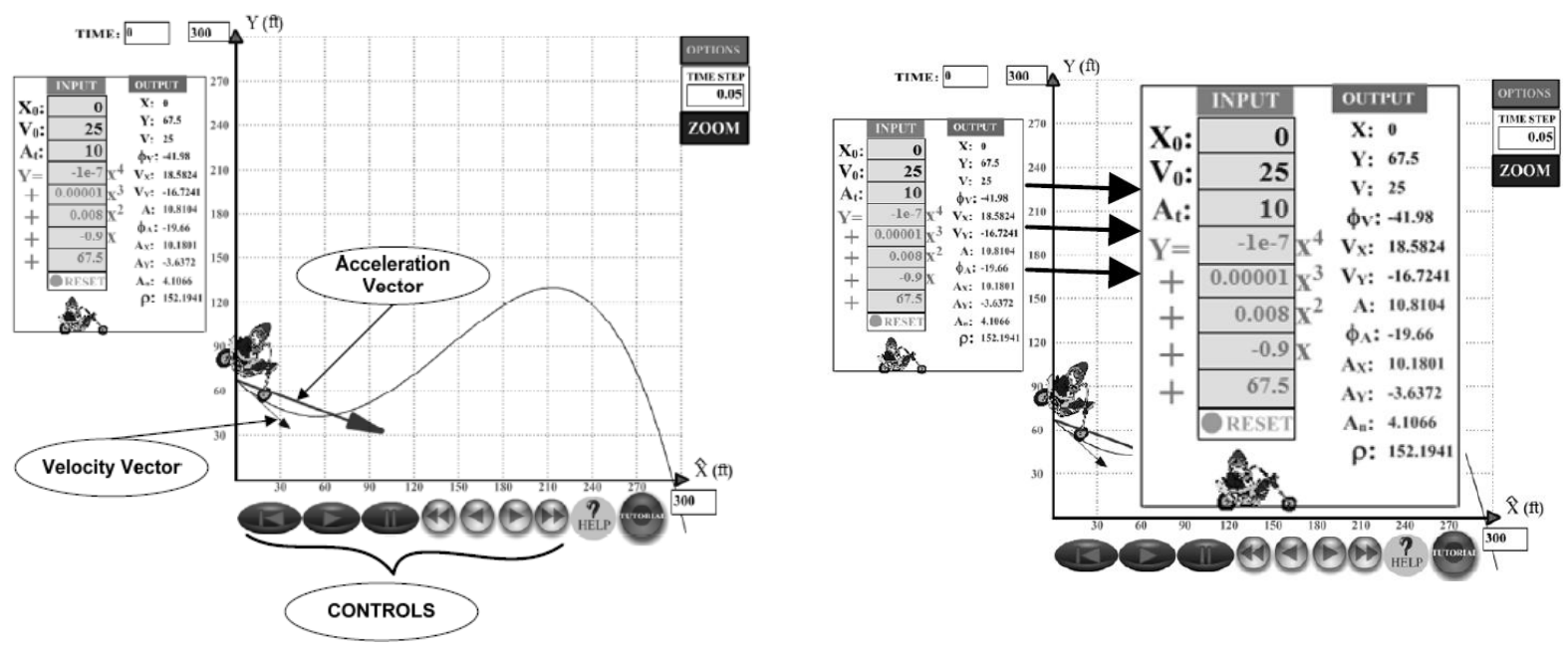

Figure 2. The animated motorcycle module and its inputs and outputs ${ }^{5}$. 


\section{Cognitive Aspects of Interactive Learning with Web-Based CSA Modules and Programs}

\section{Cognition Load Theory (CLT) and instructional animation}

Education researchers have used Cognition Load Theory (CLT) to study the effectiveness of computer simulation and animation on the human learning process, and to provide guidance for instructional animation development ${ }^{11,29,30}$. CLT considers human cognition as a natural information-processing system with long-term memory as the "central storage" and working memory as the "buffer storage." The goal of any form of instruction is to acquire organized knowledge stored in long-term memory. The more structured knowledge on a certain field that is stored in one's long-term memory, the more skillful he or she will be in that field. Working memory is limited in duration as well as in capacity for dealing with new, unfamiliar information from the outside world. This information-processing system processes three types of cognitive load: 1) intrinsic load, which refers to the intrinsic nature of the learning material; 2) extraneous load, which refers to the presentation of the learning material; and 3) germane load, which refers to the working memory resources to acquire information ${ }^{30}$.

The Cognition Load Theory offered some suggestions to make CSA modules and programs more effective. According to Hasler, Kersten \& Sweller ${ }^{29}$, the three types of cognitive load are additive, and an instructional design is considered effective when the total cognitive load is within the working memory limit of a learner. Because the intrinsic load cannot be altered, reducing extraneous load (and therefore, increasing germane load) can make instructional animation more effective. Ayres el al. ${ }^{30}$ proposed a set of strategies, such as combining statics and animation, giving the learner control over the animation pace, segmenting animation into parts, and leaving traces of the past frame's information on the computer screen. These strategies can reduce extraneous load. Most existing CSA modules and programs have given users a certain degree of control over animation and a full degree of control over the module's contents by offering functions such as navigation, stop, play, fast forward, and rewind. However, most existing CSA modules and programs provide learners with no opportunity to control (usually slow down) the speed of animation or to use the tracing strategy. These latter two strategies are especially helpful in animating complex motions in engineering dynamics education, such as a general planar motion or an object's motion after eccentric impact.

\section{Interactive web-based learning via CSA}

Interactive web-based learning serves as a supplement to a student's classroom learning experience. It provides an interactive environment similar to a traditional classroom, but provides more attention to individual students' needs. The individualized instruction, in which each student responds actively to questions and problems and receives feedback for each response, has advantages of efficiency and accelerates the learning curves of students ${ }^{32}$. The interaction enabled by the Web engages a student in the learning process, and the student also becomes selfmotivated in the discovery of new knowledge ${ }^{33}$. Greeno et al. ${ }^{24}$ noted the positive effect of computer programs' interactivities on student learning. By allowing students to manipulate and observe simulations, interactive computer programs help students construct an understanding of concepts. Activities that use a computer graphical interface are arranged to invite students to 
form conjectures about conditions in which some properties are invariant and to try to construct proofs that support those conjectures ${ }^{24}$.

The navigation buttons in CSA modules and programs enable gradual presentation of information to learners so that new information can appear step-by-step. For the CSA module used in a Soil Mechanics course at the University of Arizona ${ }^{34}$, interactive animations of key topics, especially "difficult" ones, allow students to participate in the learning process rather than be passive learners. A problem can be repeated with different values and as many times as necessary for a student to master its solution. If students have difficulty in visualizing certain key concepts at certain steps, within a mouse click, he or she receives instructions, and witnesses a visualization of that step ${ }^{34}$. As engineering mechanics courses use a lot of mathematic concepts, the step-by-step design proves very helpful in presenting the process of deriving equations and synchronizing them with animated contents ${ }^{35}$. According to Mayer and Chandler ${ }^{15}$, learners' interaction with animation and their control over the flow of instructional information allows them to acquire knowledge faster. Mayer and Chandler ${ }^{15}$ found that simple user interaction might affect both cognitive processing during learning and the cognitive outcome of learning. For cognitive processing during learning, simple user interaction reduces the learner's cognitive load on working memory and enables the learner to construct a coherent mental model. For cognitive outcomes, simple user interaction may lead to deeper understanding of scientific systems ${ }^{15}$.

\section{Cognitive theory of multimedia learning}

According to Sidhu, Ramesh, \& Selvanathan ${ }^{36}$, CSA modules and programs can be considered multimedia learning because they deliver information in multiple formats, i.e., texts, images, animations, audios, and videos. Cognitive theory of multimedia learning can be used here to explain the effect of interactive web-based CSA modules on student learning outcomes. According to Mayer \& Moreno ${ }^{37}$, learners process external representations via two separate channels: visual and auditory. Each channel has limited capacity and actively processes only a few pieces of information at any one time. The cognitive process of integrating the information from the two channels with prior knowledge takes place when the learner has corresponding pictorial and verbal representations in working memory at the same time (see Figure 3).

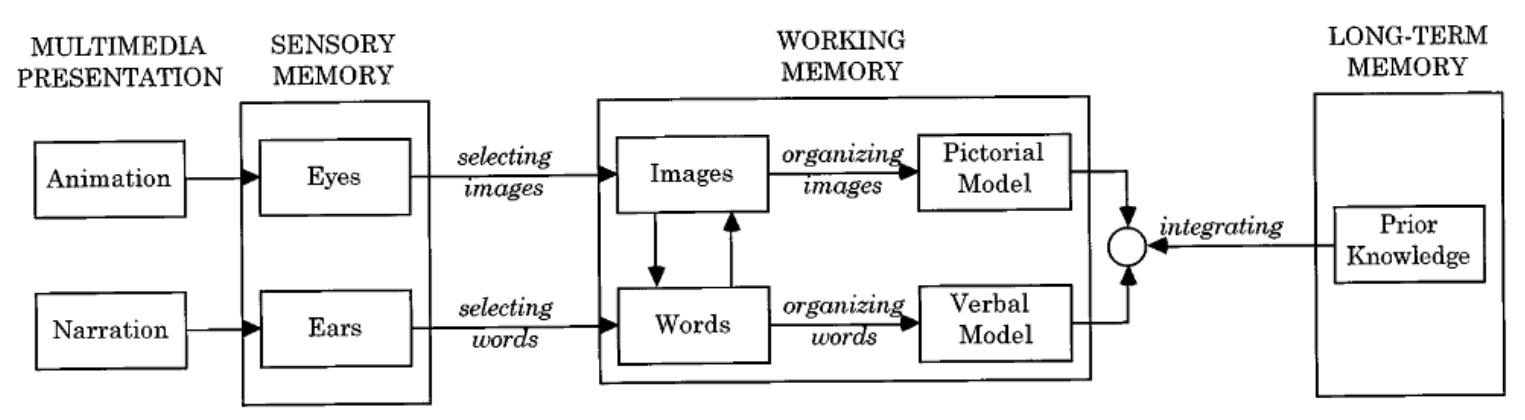

Figure 3. A cognitive theory of multimedia learning ${ }^{37}$. 
Most recently, Chan $\&$ Black ${ }^{38}$ took this theory a step further by proposing an additional multimedia representation of haptic channel to the above dual-channel model. With Chan \& Black's model of learning, learners process information from the visual and auditory channels and use their hands to interact with the content and receive immediate sensorimotor feedback about causal interactions. Chan \& Black ${ }^{38}$ conducted an experiment with 157 seventh grade students learning about Newtonian mechanics through three presentation formats: narrative-only, narrative-and-statics-visuals, and narrative-and-animation. It was revealed that directmanipulation animation, a special form of animation that incorporates the haptic channel into the learning process, helped learners facilitate their acquisition of mental models of systems ${ }^{38}$.

The approach of combining three channels of multimedia representation is utilized extensively by video game developers to create a real-world-like environment for gamers. In engineering education, there are some studies combining animation and haptic channels into multimedia learning software to enhance learners' experiences in physics, statics, and dynamics ${ }^{9,39}$. For example, in a Newton's Second Law animation of two masses (cart and box) connected by a cable, a flight joystick was used to provide feelings of the internal forces of the cart or box to the learner's hands while the learner was watching the animation on a computer screen. It was argued that haptics-augmented animation software makes student learning deeper, more fun, more compelling, and engaging. ${ }^{9}$

\section{Metacognition}

As noted by Ong \& Mannan ${ }^{40}$, web-based applications are readily available for access. Students can interact with course materials remotely from any location and progress at their own pace to study the contents of course materials. This learning process was identified as a "metacognitive" process. Metacognition refers to learners' skills to predict their own performances on various tasks and to monitor their current levels of mastery and understanding. Metacognition implies that a metacognitive approach to instruction helps students take control of their own learning by defining learning goals and monitoring their progress towards achieving learning goals ${ }^{32}$. The self-paced learning process has been implemented via a step-by-step procedure in most interactive web-based CSA modules and programs. This procedure was found to help students pursue their curiosity, review learning materials, explore more possibilities to solve a problem, and find their way to understand phenomena that are in conflict with what they learned before.

Budhu ${ }^{34}$ found that the interactive CSA modules developed by himself enhanced student learning through a self-paced, step-by-step procedure. ${ }^{34}$ As an illustration in his study, Budhu ${ }^{34}$ used Mohr's circle model in a step-by-step procedure to enhance student learning. Mohr's circle is used in engineering mechanics and other engineering disciplines to determine the stress state of a body subjected to loads. Students often have difficulty visualizing components of stresses acting on an arbitrarily selected plane through a rigid body. In the simulated, self-paced, step-bystep procedure, students clicked on a step, received instructions, and witnessed a visualization of that step. The acts of moving through an animation step-by-step with navigation buttons served as triggers of other steps or events and helped learners explore the derivation of an equation, perform online calculation with particular values, or draw graphs with selected parameters. Greeno et al. ${ }^{24}$ and Vos \& Graaff ${ }^{41}$ also referred to this active learning attitude as metacognition. 


\title{
Development of Interactive Web-Based CSA Modules and Programs
}

\author{
Authoring tools, development software, and accessibility
}

Developers use proper software or collections of software components, called Authoring Tools, to create or modify web content for use by other people. Authoring tools allow developers to publish to the World Wide Web, to be read by people from all over the world, in many different languages and on many different computers across browser platforms ${ }^{43}$. Authoring tools have been employed to write the web, from WYSIWYG HTML editors through software for updating social media profiles, micro-blogging, and photo and video sharing to development kits like Adobe Flash. Free or partially free software, such as some versions of C++, HTML editors, DirectX, and OpenGL, are also used by educators to develop CSA modules and programs.

Some engineering educators have used commercially available software packages in teaching their courses. These commercial software packages are multi-physics or multi-body solvers, such as ANSYS and MSC Adams which can simulate many scientific and engineering problems in a variety of engineering fields. The CSA modules developed based on these software packages require proprietary compatible software on users' computers to play animation. These commercial software packages are powerful, and instructors do not need to spend financial and human resources to develop CSA modules and programs. In addition, students have an opportunity to learn high-end simulation packages that they will use in senior level courses and in professional careers later on ${ }^{43}$. However, because the commercial software packages are comprehensive and require users to have full knowledge about the domain and to take time to learn, the upfront and maintenance costs of these proprietary software packages are expensive and can be afforded by large institutions only.

Commenting about Working Model, a proprietary simulation package in mechanics, Flori, Koen, $\&$ Oglesby ${ }^{28}$ noted that: "there are some drawbacks to using it in the first course in engineering mechanics" for the above reasons. These modules may be suitable for lab computers on campuses or distributed sparingly to lecturers for class presentations, as in the case of Cornwell ${ }^{2}$ and Mazzei ${ }^{43}$. Therefore, CSA modules and programs derived from proprietary software packages are inaccessible to most students once they are off campus, or if they are from small and remote colleges.

The accessibility of web-based CSA modules and programs from the client side is an important construct for any animation developer. As the norm of today' networking technology, in order to be widely accessed through the Internet, simulation and animation modules and programs need to be run on any Internet-ready computer from anywhere and at any time. An approach to addressing the issues of software proprietary and accessibility is using Web plug-ins such as Java applet, Shockwave, or Flash players. These players and plug-ins are free, pre-installed, and constantly updated in the most common web browsers, such as Internet Explorer, Firefox, Chrome, and Safari. This means that simulation and animation modules written for these plugins would be viewable by all visitors anytime and anywhere ${ }^{40}$.

In addition, Stanley ${ }^{4,28}$ argued that development costs may be the main reason why there is no interactive CSA software developed in the mass scale for engineering education. Flori et al. ${ }^{27}$ 
who developed Mechanics Software at the University of Missouri-Rolla, noted that "developing these courses is resource-intensive" but considered the cost to be worth it because these computer programs could offer "less faculty commitment than traditional lecture-based lectures." This is also the main approach that most engineering educators have used in recent years. Of the eleven studies relating to CSA modules reviewed in this paper, $82 \%(\mathrm{n}=11)$ reported the use of one or more free plug-ins to display their animation programs on the client side (see Appendices A and B). Web-based interactive animation software may be developed either by creating Java applets or by writing code in Adobe Flash Action Script ${ }^{3,4,6}$.

\section{Mathematic equations presentation and reusability}

According to Enelund \& Larsson ${ }^{44}$, explicit mathematic equations, along with animated contents, helped students gain self-confidence in using the CSA modules and programs. Mathematic expressions, user inputs, and interactivities helped students understand the mathematic principles behind simulation and animation, instead of, as Enelund \& Larsson 44 stated, "running black box simulations with ready-made programs." As engineering mechanics courses use a lot of mathematic concepts, the presentation of mathematic equations is a crucial part of a CSA module or program. Some CSA modules and programs show final equations as parts of learning modules. Other CSA modules and programs utilize the interactive functionality of navigation buttons to show step by step the deriving process of mathematical equations along with animated graphics. For example, in the case of Structural Analysis (Figure 4), Sidhu et al. ${ }^{7}$ used different animation techniques (changing colors, alpha values, and arrows' directions and magnitudes) to show students various steps involved in analyzing the equations of equilibrium for forces and moments acting on a structure's components.

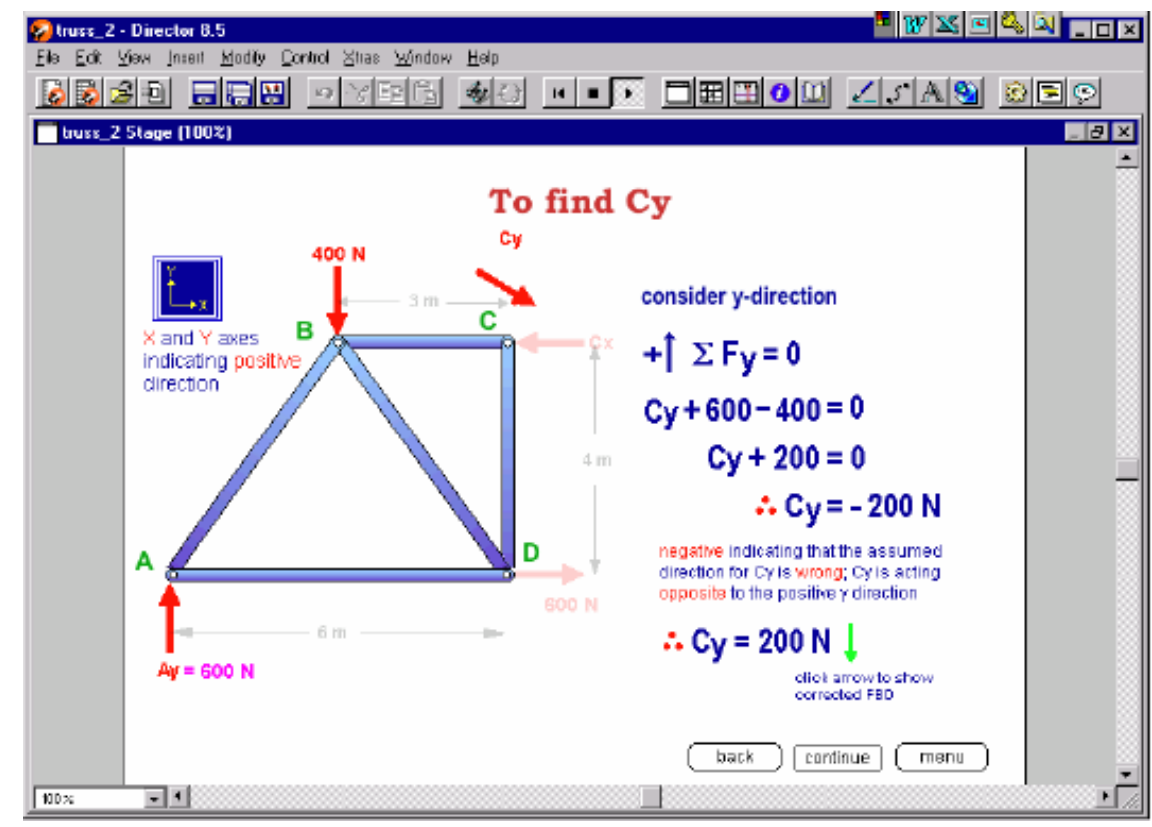

Figure 4. Different animation techniques help student visualize steps to calculate forces and moments acting on a structure's components 7 . 
Furthermore, computers are heavily used to support the learning activities of today's students, such as doing research, reading course materials, accessing and submitting course assignments, and even taking notes. Therefore, students need a seamless learning environment where they can copy and paste contents among applications, or copy contents from learning materials and paste them to their own notes for further self-study or lab reports, and so on. According to Humar et al. $^{35}$, the reusability of CSA modules and program contents, especially mathematic equations, via "copy-and-paste" activities combined with the possibility of modifying equations and parameters "can encourage students to make further calculations by themselves and thus investigate a problem more seriously." While Flash players and Java applets will not permit "copy-and-paste," MathML along with HTML or other markup languages can serve these functionalities.

\section{Study Characteristics of Published Literature}

The present study analyzed nine study characteristics among 11 published studies on the development and assessments of CSA modules and programs in engineering mechanics. These characteristics include 1) commonly-reported student learning outcomes; 2) sample sizes; 3) area of study; 4) authoring tools, development software, and proprietary software on the client side; 5) mathematic equation presentation; 6) user control; 7) other media besides animation; 8) experimental design; and 9) data collection methods. These characteristics are analyzed in detail in the following paragraphs.

1) Commonly-reported student learning outcomes: Nearly all published studies reported that CSA modules and programs enhanced student learning $(91 \%, \mathrm{n}=11)$ and student spatial visualization skills $(82 \%, \mathrm{n}=11)$. Seven studies $(64 \%)$ claimed that CSA modules and programs increased student enjoyment, while three studies (27\%) reported that CSA modules and programs motivated students to learn. In one study, students showed strong dissatisfaction after using a CSA module. Students disagreed or strongly disagreed that the module helped them learn and visualize the concepts involved ${ }^{3}$. It was concluded that poorly-designed user interface and interactive functions might have been the main causes making the module ineffective.

2) Sample sizes: Of the eleven studies reviewed, two studies $(18 \%, \mathrm{n}=11)$ had sample sizes of fewer than 50, four (37\%) had sample sizes from 51 to 100 , and three (27\%) had sample sizes over 100. In addition, two studies (18\%) reported "students taking the courses/sections" instead of specific numbers. Therefore, more than half of these studies were conducted with less than 100 student participants. The researchers typically assigned student participants from the same class or section at the time of conducting their research study.

3) Area of study: Most of the reviewed studies investigated the use of CSA modules and programs in learning dynamics $(72 \%, \mathrm{n}=11)$. Two studies reported the use of CSA modules and programs in learning statics $(9 \%)$, and high school physics $(9 \%)$, respectively.

4) Authoring tools, development software, and proprietary software on the client side: Of the eleven studies examined in the present study, only two researchers used commercial simulation packages in teaching their courses, accounting for $18 \%(\mathrm{n}=11)$ of the studies. Eighty-two percent of the studies used authoring software such as Adobe Flash (27\%), Macromedia products (now acquired by Adobe) (28\%), or a combination of partially-free or free software, such as 
C++, Java, VRML, and HTML (27\% of all cases), to develop CSA modules and programs. It was found that $82 \%$ of web-based CSA modules and programs made use of the availability of software plug-ins that were pre-installed (and easily updated) in most common web browsers and provided wide accessibility to students, and that $18 \%$ required some sorts of proprietary modules on the client side to display computer simulation and animation. According to a recent survey from Adobe in several countries, Flash player and Java plug-in, two free web browser plug-ins, are available in $99 \%$ and $73 \%$ of Internet enabled PCs, respectively ${ }^{45}$.

5) Mathematic equation presentation: Of the eleven articles examined, seven studies (64\%) showed mathematic equations, along with animated graphics, in their CSA modules and programs. The other four studies (36\%) just showed animations or animations with inputs and outputs. The former group may be used as standalone learning units, whilst the latter group may be used to assist student learning along with students' own notes or other learning materials.

6) User control: Most CSA modules and programs provided users with plenty of control. Seventy-three percent of studies $(\mathrm{n}=11)$ permitted learners to control animation features at basic levels such as "Stop," "Play," etc. Ninety-one percent of studies permitted learners to navigate module contents via buttons such as "Next," "Back," "Fast Forward," etc. Another 91\% permitted learners to change the values of input variables to investigate modules and verify learners' own parameters. One CSA program permitted learners to view animation results from different angle views, giving learners an opportunity to explore the objects in 3D space ${ }^{46}$.

7) Other media employed in CSA modules and programs: Two programs (18\% of all studies) used videos, one program (9\%) used haptics as additional multimedia channels besides animation, and eight programs (73\%) use only animation in the CSA programs. According to the cognitive theory of multimedia learning, videos are also a form of visual presentation of learning materials. The information from animation and the information from video share the same visual channel to enter a learner's working memory. Therefore, video features in a computer animation program provide learners with other visual iterations of the same content and may not reduce extraneous cognitive load. The haptic channel requires haptic interfaces and devices to provide realistic touch sensations coordinated with on-screen animation (e.g. force feedback joysticks). None of the 11 studies examined presented learning content in both animation and narration.

8) Experimental design: Most of the studies (9 of 11 cases, or 82\%) employed One-Shot Case Study design. One study (9\%) dealt with Static Group Comparison design, and another study (9\%) used One-Group Pretest-Posttest design. The classification of experimental designs in educational research is based on the work by Gall, Gall \& Borg ${ }^{47}$. In One-Shot Case Study design, the learning with CSA modules and programs (i.e., experimental treatment) was administered to a single group of students (or groups of students who were also treated as a single group because all received the same treatment). Then a posttest and a questionnaire survey were administered to measure the effects of CSA modules and programs. In Static Group Comparison design, only students in the experimental group worked with the CSA module; whilst students in the control group did not. Posttests were implemented in both groups to measure the effectiveness of CSA modules and programs. In One-Group Pretest-Posttest design, no control group was involved, and pretests and posttests were administrated to a single group of students. 
The problem with the above-described experimental designs is that student groups in these designs were formed based on convenience (students in a classroom or a section) rather than based on a random assignment. Gall et $\mathrm{al}^{47}$ noted that: "experiments with random assignment are highly recommended by most educators because they provide strong assurance that observed effects are caused by experimental treatment and not by extraneous variables." As for One-Shot Case Study design, Gall et al. ${ }^{47}$ found that it had low internal validity and "yields meaningless findings." Hoffler \& Neuter ${ }^{11}$ noted possible extraneous variables such as prior knowledge, spatial skills, motivation, and learners' time spent on tasks, could also affect student learning outcomes with CSA modules and programs.

9) Data collection methods: The methods used in collecting data in the 11 studies included questionnaires $(100 \%, \mathrm{n}=11)$, content analysis of students' comments $(36 \%)$, and scores of performance tests (quizzes) (21\%).

\section{Suggestions and Conclusions}

This paper has presented a critical literature review and analysis of interactive web-based CSA modules and programs employed in engineering mechanics education. Representative online CSA modules can also be found in Internet ${ }^{50,51}$. The results show that CSA enhanced students' spatial visualization skills, improved their understanding of learning materials, and aroused their interest in learning. Many published studies reported that CSA helped students visualize complex phenomena in engineering mechanics, and explicitly showed the relationships among various components of a complex system over time and space.

Cognitive Load Theory and cognitive theory of learning multimedia have been employed to explain the CSA-based learning process and have offered suggestions to make CSA modules and programs more effective. It is found that many existing CSA modules and programs developed for engineering mechanics were not designed in a way in which cognitive principles associated with Cognitive Load Theory could be adequately addressed in order to reduce cognitive load and hence enhance student learning more effectively. Some technical aspects involved in the development of interactive CSA modules and programs have also been discussed in this paper. To maximize student learning outcomes, it is suggested that particular attention be paid to control students' cognitive load at an appropriate level when designing and implementing CSA modules.

Finally, based on 11 published relevant studies, this paper has analyzed nine study characteristics among these published studies. The results show that:

1) Nearly all published studies reported that CSA modules and programs enhanced student learning $(91 \%, \mathrm{n}=11)$ and student spatial visualization skills $(82 \%, \mathrm{n}=11)$.

2) More than a half of published studies were conducted with less than 100 student participants.

3) Most of the reviewed studies investigated the use of CSA modules and programs in learning dynamics $(72 \%, \mathrm{n}=11)$, rather than in learning statics.

4) Eighty-two percent of the reviewed studies used authoring software, such as Adobe Flash (27\%), Macromedia products (now acquired by Adobe) (27\%), or a combination of free or 
partially free software (such as C++, Java, VRML, and HTML) to develop CSA modules and programs.

5) Of the eleven articles examined, seven studies (64\%) showed mathematic equations, along with animated graphics, in their CSA modules and programs.

6) Most CSA modules and programs provided users with plenty of control.

7) In addition to animation, other media employed in CSA modules and programs included videos and haptics.

8) Most of the studies ( 9 of 11 cases, or 82\%) employed a One-Shot Case Study design in which only a single group of students were involved (that is with no comparison group).

9) The data collection methods used in the 11 studies included questionnaires $(100 \%, \mathrm{n}=11)$, content analysis of students' comments (36\%), and scores of performance tests (quizzes) $(21 \%)$.

\section{Acknowledgements}

This material is based upon work supported by the National Science Foundation under Grant No. DUE 1122654.

\section{Bibliography}

[1] Michau F., Gentil S., \& Barrault M., 2001, "Expected Benefits of Web-Based Learning for Engineering Education: Examples in Control Engineering," European Journal of Engineering Education, 26 (2), pp. 151168.

[2] Cornwell, P. J., 2000, "Dynamics Evolution - Chance or Design," Proceedings of the 2000 ASEE Annual Conference \& Exposition, St. Louis, Missouri.

[3] Fong, D. B., 2008, "A Visual Simulation Playground for Engineering Dynamics," Master Thesis, Texas A\&M University.

[4] Stanley, R., 2008, "Interactive Web Based Animation Software: An Efficient Way to Increase the Engineering Student's Fundamental Understanding of Particle Kinematics and Kinetics," Proceedings of ASEE Zone 1 Conference, West Point, NY.

[5] Stanley, R., 2009, “A Way to Increase the Engineering Student's Qualitative Understanding of Particle Kinematics and Kinetics by Utilizing Interactive Web Based Animation Software," Proceedings of the 2009 ASEE Annual Conference \& Exposition, Austin, TX.

[6] Hubing, N., Oglesby, D. B., Philbot, T. A., Yellamraju, V., Hall, R. H., \& Flori, R. E., 2002, "Interactive Learning Tools: Animating Statics," Proceedings of the 2002 ASEE Annual Conference \& Exposition, Montreal, Canada.

[7] Sidhu, M. S., Ramesh, S., \& Selvanathan, N., 2004, "The Multimedia Approach in Visualization Engineering Concept," International Journal of Computing and Information Sciences, 2(3), pp. 129-136.

[8] Deliktas, B., 2011, "Computer Technology for Enhancing Teaching and Learning Modules of Engineering Mechanics," Computer Application in Engineering Education, 19(3), pp. 421-432.

[9] Williams II, R. L., He, X., Franklin, T., \&Wang, S., 2007, "Haptics-Augmented Engineering Mechanics Educational Tools," World Transactions on Engineering and Technology Education, 6(1), pp. 27-30.

[10] Rhymer, D., Jensen, D., Bowe, M., 2001, "An Assessment of Visualization Modules for Learning Enhancement in Mechanics," Proceedings of the 2001 ASEE Annual Conference \& Exposition, Albuquerque, NM.

[11] Hoffler, T. N., Leutner, D., 2007, "Instructional Animation Versus Static Pictures: A Meta-Analysis," Learning and Instruction, 17 (6), pp. 722-738. 
[12] Betrancourt, M., \& Tversky, B., 2000, "Effect of Computer Animation on Users' Performance: A review," Le Travail Humain, 63(4), pp. 311-329.

[13] Betrancourt, M., 2005, "The Animation and Interactivity Principles in Multimedia Learning," In Mayer (ed.), The Cambridge Handbook of Multimedia Learning, (pp.287 -296), New York: Cambridge.

[14] Paas, F., \& van Merriënboer, J. J. G., 1994, "Instructional Control of Cognitive Load in the Training of Complex Cognitive Tasks. Educational Psychology Review, 6, pp. 357-371.

[15] Mayer, R. E., \& Chandler, P., 2001, "When Learning Is Just One Click Away: Does Simple User Interaction Foster Deeper Understanding of Multimedia Messages?” Journal of Educational Psychology, 93 (2), pp. 390397.

[16] Larive, C. K., 2008, "A Picture is Worth a Thousand Words: Animations and Simulations in the Teaching of Analytical Science," Analytical and Bioanalytical Chemistry, 390, pp. 71-75.

[17] Homer, B. D., \& Hayward, E. O., 2009, "Design Factors for Educationally Effective Animations and Simulations," Journal of Computing in Higher Education, 21(1), pp. 31-61.

[18] Rieber, L. P., Tzeng, S. C., \& Tribble, K., 2004, "Discovery Learning, Representation, and Explanation Within a Computer-Based Simulation: Finding the Right Mix," Learning and Instruction, 14, pp. 307-323.

[19] Curotto, C. L., \& Gramoll, K. C., 2012, "Dynamics Simulation Using Server Cluster Technology," Proceedings of the 2012 ASEE Annual Conference \& Exposition, San Antonio, Texas.

[20] Mohler, J. L., 2001, "Using Interactive Multimedia Technologies to Improve Students Understanding of Spatially-dependent Engineering Concepts," Proceeding of 2001 International Conference on Computer Geometry and Graphics, Nyzhny Novgorod, pp. 292- 300.

[21] Sorby, S. A., Drummer, T., Hungwe, K., \& Charlesworth, P., 2005, "Developing 3-D Spatial Visualization Skills for Non-Engineering Students," Proceedings of the 2005 ASEE Annual Conference \& Exposition, Portland, OR.

[22] Brown, D., 2001, "Cognitive Science Concepts and Technology Teacher Education," Journal of Technology Studies, 27 (1), pp. 33-42.

[23] Blasko, D. G., Holliday-Darr, K., Mace, D., \& Blasko-Drabik, H., 2004, "VIZ: The Visualization Assessment and Training Web Site," Behavior Research Methods, Instruments, \& Computers, 36 (2), pp. 256-260.

[24] Greeno, J., Collins, A., \& Resnick, L., 1996, "Cognition and Learning,” Handbook of Educational Psychology. (pp. 15-46). New York, NY: Macmillan.

[25] Hibbeler, R. C., 2010, Engineering Mechanics-Dynamics, Upper Saddle River, NJ: Pearson Prentice Hall.

[26] Ruiz, J. G., Cook, D. A., \& Levinson, A. J., 2009, "Computer Animations in Medical Education: A Critical Literature Review," Medical Education, 43, pp. 838-846.

[27] Flori, R. E., Koen, M. A., Oglesby, D. B., 1996, "Basic Engineering Software for Teaching (BEST) Dynamics," ASEE Journal of Engineering Education, pp. 61-67.

[28] Stanley, R., 2008, “An Efficient Way to Increase the Engineering Student's Fundamental Understanding of Particle Kinematics and Kinetics by Utilizing Interactive Web Based Animation Software," ASEE Computers in Education Journal, 18(3), pp. 23-41.

[29] Hasler, B. S., Kersten, B. \& Sweller, J., 2007, "Learner Control, Cognitive Load and Instructional Animation," Applied Cognition Psychology, 21, pp. 713-729.

[30] Ayres, P., Kalyuga, S., Marcus, N., \& Sweller, J., 2005, "The Conditions Under Which Instructional Animation May Be Effective," International Workshop and Mini-conference, Open University of the Netherlands.

[31] McIntyre, D. R., \& Wolff, F.G., 1998, “An Experiment with WWW Interactive Learning in University Education," Computers \& Education, 31, pp. 255-264.

[32] Bransford, J. D., Brown, A. L., \& Cocking, R. R. (Eds), 2000, "Learning: From Speculation to Science," How People Learn - Brain, Mind, Experience, and School, (pp 2-25). Washington DC: National Academy Press.

[33] Oreta, A. W. C., 1999, "Developing a Web-Based Learning Module in a Basic Civil Engineering Course," Computer Applications in Engineering Education, 7(4), pp. 235-243.

[34] Budhu, M., 2001, "Enhancing Instructions Using Interactive Multimedia Simulations," Simulation, 76 (4), pp. 222-231.

[35] Humar, I., Sinigoj, A. R., Bester, J., \& Hagler M. O., 2005, "Integrated Component Web-Based Interactive Learning Systems for Engineering," IEEE Transaction on education, 48 (4), pp. 664-675.

[36] Sidhu, M. S., Ramesh, S., \& Selvanathan, N., 2005, "A Multimedia Visualizing Tool For Solving Mechanics Dynamics Problem," International Journal of Interactive Educational Multimedia, 10, pp. 78 - 89.

[37] Mayer, R. E., \& Moreno, R., 2002, “Animation as an Aid to Multimedia Learning," Educational Psychology Review, 14 (1), pp. 87-99. 
[38] Chan, M.S., \& Black, J. B. (2006). Direct-Manipulation Animation: Incorporating the Haptic Channel in the Learning Process to Support Middle School Students in Science Learning and Mental Model Acquisition. In Proceedings of the 7th international conference on Learning sciences (ICLS '06), International Society of the Learning Sciences, pp. 64-70.

[39] Williams II, R. L., Chen, M. Y., \& Seaton, J. M., 2002, "Haptics-Augmented High School Physics Tutorials," International Journal of Virtual Reality, 5(1), Retrieve from http://www.ohio.edu/people/williar4/html/PDF/IJVR2001.pdf.

[40] Ong, S. K., \& Mannan, M.A., 2003, "Virtual Reality Simulations and Animations in a Web-Based Interactive Manufacturing Engineering module," Computer \& Education, 43, pp. 361-382.

[41] Vos, H. \& Graaff, E.D., 2004, "Developing Metacognition: a Basis for Active Learning," European Journal of Engineering Education, 29 (4), pp. 543-548.

[42] The World Wide Web Consortium, 2012, "Authoring Tools, Social Media," Retrieved on December 31, 2012 from: http://www.w3.org/standards/agents/authoring.

[43] Mazzei, A., 2003, "Integrating Simulation Software into an Undergraduate Dynamics Course: A Web-Based Approach," Proceedings of the 2003 ASEE Annual Conference \& Exposition, Nashville, TN.

[44] Enelund, M. \& Larsson, S., 2006. "A computational mathematics education for students of mechanical engineering," World Transactions on Engineering and Technology Education, 5(2), pp. 329-332.

[45] Adobe, 2012, "Statistic: PC Penetration," Retrieved on December 31, 2012 from: http://www.adobe.com/de/products/flashplatformruntimes/statistics.html.

[46] Aziz, E. S., Esche, S., \& Chassapis, C., 2007, "Enhancing the Learning Experience Using Simulation and Experimentation to Teach Mechanical Vibrations," Proceedings of the 2007 ASEE Annual Conference \& Exposition, Honolulu, HI.

[47] Gall, M. D., Gall, J. P., \& Borg, W. R., 2007, “Educational Research: An Introduction,” 8th edition, New York, NY: Pearson Education.

[48] Sidhu, M. S., 2007, "Architecture of Technology Assisted Problem Solving Packages for Engineering," World Transactions Journal on Engineering and Technology Education, 6 (2), pp. 373 - 376.

[49] Fang, N., 2012, "Using Computer Simulation and Animation to Improve Student Learning of Engineering Dynamics," Proceedings of the 4th Regional Conference on Engineering Education (RCEE 2012) and Research in Higher Education 2012 (RHEd 2012), Johor, Malaysia, April 10-12, 2012.

[50] http://randjanimations.com/Wiley_Flash_Development/wiley_samples_for_review.html, accessed on March $13,2013$.

[51] http://randjanimations.com/Wiley_Flash_Development/wiley_sample_dynamics_problems.htm, accessed on March 13, 2013. 


\section{Appendix A: Study characteristics related to CSA modules and programs}

\begin{tabular}{|c|c|c|c|c|c|c|c|c|c|c|}
\hline$\frac{\vec{E}}{E}$ & 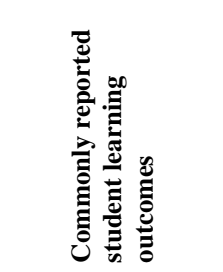 & 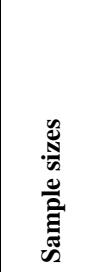 & 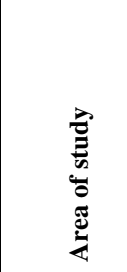 & 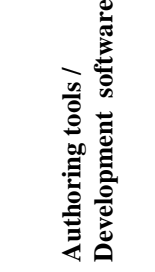 & 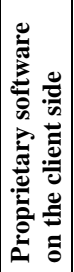 & 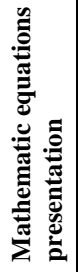 & 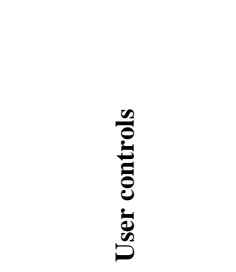 & 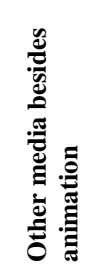 & 预 & 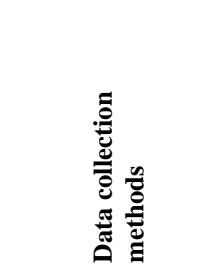 \\
\hline $\begin{array}{l}\text { Flori et al. } \\
(1996)^{27}\end{array}$ & $\begin{array}{l}\text { * Enhance learning } \\
* \text { Enhance spatial } \\
\text { visualization } \\
* \text { Gain Enjoyment } \\
* \text { Gain Motivation }\end{array}$ & $\begin{array}{l}50 \\
(1994) \\
85 \\
(1995) \\
\text { (note 1) }\end{array}$ & Dynamics & $\begin{array}{l}\text { Macromedia } \\
\text { Flash }\end{array}$ & $\mathrm{N}$ & $\mathrm{Y}$ & $\begin{array}{l}\text { * Animation control } \\
* \text { Content Control } \\
* \text { User inputs }\end{array}$ & None & $\begin{array}{l}\text { One-Shot } \\
\text { Case Study }\end{array}$ & * Questionnaire \\
\hline $\begin{array}{l}\text { Cornwell } \\
(2000)^{2}\end{array}$ & $\begin{array}{l}* \text { Enhance learning } \\
* \text { Enhance spatial } \\
\text { visualization } \\
* \text { Gain Enjoyment } \\
* \text { Gain Motivation }\end{array}$ & $\begin{array}{l}\text { Other } \\
\text { (note 2) }\end{array}$ & Dynamics & $\begin{array}{l}\text { Working } \\
\text { Model }\end{array}$ & $\mathrm{Y}$ & $\mathrm{N}$ & $\begin{array}{l}\text { * Animation control } \\
\text { * Content Control }\end{array}$ & None & $\begin{array}{l}\text { One-Shot } \\
\text { Case Study }\end{array}$ & * Questionnaire \\
\hline $\begin{array}{l}\text { Hubing et al. } \\
(2002)^{6}\end{array}$ & $\begin{array}{l}* \text { Enhance learning } \\
* \text { Enhance spatial } \\
\text { visualization } \\
* \text { Gain Motivation }\end{array}$ & 51 & Statics & Adobe Flash & $\mathrm{N}$ & $\mathrm{Y}$ & $\begin{array}{l}\text { * Animation control } \\
* \text { Content Control } \\
* \text { User inputs }\end{array}$ & None & $\begin{array}{l}\text { Static Group } \\
\text { Comparison } \\
\text { Design }\end{array}$ & $\begin{array}{l}\text { * Comment content } \\
\text { analysis } \\
\text { * Performance Test } \\
\text { * Questionnaire }\end{array}$ \\
\hline $\begin{array}{l}\text { Mazzei } \\
(2003)^{43}\end{array}$ & $\begin{array}{l}* \text { Enhance learning } \\
* \text { Enhance spatial } \\
\text { visualization } \\
* \text { Gain Enjoyment }\end{array}$ & 100 & Dynamics & MSC Adams & $\mathrm{Y}$ & $\mathrm{Y}$ & $\begin{array}{l}\text { * Content Control } \\
\text { * User inputs }\end{array}$ & None & $\begin{array}{l}\text { One-Shot } \\
\text { Case Study }\end{array}$ & * Questionnaire \\
\hline $\begin{array}{l}\text { Sidhu, } \\
\text { Ramesh, \& } \\
\text { Selvanathan } \\
(2005)^{7} \\
\text { (note 3) }\end{array}$ & $\begin{array}{l}* \text { Enhance learning } \\
* \text { Enhance spatial } \\
\text { visualization } \\
* \text { Gain Enjoyment }\end{array}$ & $\begin{array}{l}\text { Other } \\
\text { (note 4) }\end{array}$ & Dynamics & $\begin{array}{l}\text { Macromedia } \\
\text { Director }\end{array}$ & $\mathrm{N}$ & $\mathrm{Y}$ & $\begin{array}{l}* \text { Animation control } \\
* \text { Content Control } \\
* \text { User inputs }\end{array}$ & None & $\begin{array}{l}\text { One-Shot } \\
\text { Case Study }\end{array}$ & * Questionnaire \\
\hline
\end{tabular}




\begin{tabular}{|c|c|c|c|c|c|c|c|c|c|c|}
\hline $\begin{array}{l}\text { William et } \\
\text { al. (2007) }\end{array}$ & * Enhance learning & 26 & $\begin{array}{l}\text { High school } \\
\text { Physics }\end{array}$ & $\begin{array}{l}\text { Free or } \\
\text { partially free } \\
\text { (HTML, C++, } \\
\text { DirectX, and } \\
\text { OpenGL) }\end{array}$ & $\mathrm{N}$ & $\mathrm{N}$ & $\begin{array}{l}* \text { Animation control } \\
* \text { Content Control } \\
* \text { User inputs }\end{array}$ & Haptic & $\begin{array}{l}\text { One-Shot } \\
\text { Case Study }\end{array}$ & $\begin{array}{l}* \text { Comment content } \\
\text { analysis } \\
* \text { Questionnaire }\end{array}$ \\
\hline $\begin{array}{l}\text { Ariz et al. } \\
(2007)^{46}\end{array}$ & $\begin{array}{l}* \text { Enhance learning } \\
* \text { Enhance spatial } \\
\text { visualization } \\
* \text { Gain Enjoyment }\end{array}$ & 16 & Dynamics & $\begin{array}{l}\text { Free or } \\
\text { partially free } \\
\text { (VRML, Java, } \\
\text { and Jython) }\end{array}$ & $\mathrm{N}$ & $\mathrm{Y}$ & $\begin{array}{l}\text { * Animation control } \\
* \text { Content Control } \\
\text { * User inputs }\end{array}$ & Video & $\begin{array}{l}\text { One-Shot } \\
\text { Case Study }\end{array}$ & * Questionnaire \\
\hline Fong (2008) & & 94 & Dynamics & $\begin{array}{l}\text { Free or } \\
\text { partially free } \\
(\mathrm{C}++ \text { and } \\
\text { GDI+) }\end{array}$ & $\mathrm{N}$ & $\mathrm{N}$ & * User inputs & None & $\begin{array}{l}\text { One-Shot } \\
\text { Case Study }\end{array}$ & $\begin{array}{l}* \text { Comment content } \\
\text { analysis } \\
* \text { Questionnaire }\end{array}$ \\
\hline $\begin{array}{l}\text { Stanley } \\
(2008,2009) \\
4,5\end{array}$ & $\begin{array}{l}* \text { Enhance learning } \\
* \text { Enhance spatial } \\
\text { visualization } \\
* \text { Gain Enjoyment }\end{array}$ & 70 & Dynamics & Adobe Flash & $\mathrm{N}$ & $\mathrm{N}$ & $\begin{array}{l}* \text { Animation control } \\
* \text { Content Control } \\
* \text { User inputs }\end{array}$ & None & $\begin{array}{l}\text { One-Shot } \\
\text { Case Study }\end{array}$ & * Questionnaire \\
\hline $\begin{array}{l}\text { Deliktas } \\
(2011)^{8}\end{array}$ & $\begin{array}{l}* \text { Enhance learning } \\
* \text { Enhance spatial } \\
\text { visualization } \\
* \text { Gain Enjoyment }\end{array}$ & 383 & $\begin{array}{l}\text { Engineering } \\
\text { Mechanics }\end{array}$ & $\begin{array}{l}\text { Macromedia } \\
\text { Flash }\end{array}$ & $\mathrm{N}$ & $\mathrm{Y}$ & $\begin{array}{l}* \text { Animation control } \\
* \text { Content Control } \\
* \text { User inputs }\end{array}$ & Video & $\begin{array}{l}\text { One-Shot } \\
\text { Case Study }\end{array}$ & * Questionnaire \\
\hline$\underset{49}{\text { Fang }}(2012)$ & $\begin{array}{l}\text { * Enhance learning } \\
* \text { Enhance spatial } \\
\text { visualization }\end{array}$ & 304 & Dynamics & Adobe Flash & $\mathrm{N}$ & $\mathrm{Y}$ & $\begin{array}{l}\text { * Content Control } \\
* \text { User inputs }\end{array}$ & None & $\begin{array}{l}\text { One-Group } \\
\text { Pretest- } \\
\text { Posttest } \\
\text { Design }\end{array}$ & $\begin{array}{l}\text { * Comment content } \\
\text { analysis } \\
\text { * Performance Test } \\
\text { * Questionnaire }\end{array}$ \\
\hline
\end{tabular}

Notes: ${ }^{(1)}$ : Number of students in questionnaire survey (1993) was reported as "students in the courses," no specific number found.

(2): Numbers of students in questionnaire surveys $(1994,1999)$ were reported as "students in the courses," no specific number found.

${ }^{(3)}$ : Numbers of students in questionnaire surveys (2004) were reported as "students in the courses," no specific number found.

${ }^{(4)}$ : The package can work alone on PCs or be put on web servers to distribute to users ${ }^{48}$. 


\section{Appendix B: Summary of Literature Review}

\begin{tabular}{|c|c|c|c|}
\hline \multicolumn{2}{|c|}{ Study Characteristic } & \multirow{2}{*}{$\begin{array}{c}\text { Frequency } \\
10 \\
\end{array}$} & \multirow{2}{*}{$\begin{array}{c}\text { Percentage } \\
91 \%\end{array}$} \\
\hline Commonly reported student & Enhance learning & & \\
\hline & Enhance spatial visualization & 9 & $82 \%$ \\
\hline & Gain enjoyment & 7 & $64 \%$ \\
\hline & Gain motivation & 3 & $27 \%$ \\
\hline \multirow[t]{4}{*}{ Sample sizes } & $<50$ & 2 & $18 \%$ \\
\hline & $51-100$ & 4 & $37 \%$ \\
\hline & $>101$ & 3 & $27 \%$ \\
\hline & Other reported number & 2 & $18 \%$ \\
\hline \multirow[t]{4}{*}{ Area of study } & Engineering mechanics & 1 & $9 \%$ \\
\hline & High school physics & 1 & $9 \%$ \\
\hline & Dynamics & 8 & $73 \%$ \\
\hline & Statics & 1 & $9 \%$ \\
\hline \multirow{6}{*}{$\begin{array}{l}\text { Authoring tools / } \\
\text { development software }\end{array}$} & Adobe Flash & 3 & $27 \%$ \\
\hline & Macromedia Director & 1 & $9 \%$ \\
\hline & Macromedia Flash & 2 & $19 \%$ \\
\hline & MSC Adams & 1 & $9 \%$ \\
\hline & Free or partially free & 3 & $27 \%$ \\
\hline & Working Model & 1 & $9 \%$ \\
\hline \multirow{2}{*}{$\begin{array}{l}\text { Proprietary software } \\
\text { on the client side }\end{array}$} & Yes & 2 & $18 \%$ \\
\hline & No & 9 & $82 \%$ \\
\hline \multirow{2}{*}{$\begin{array}{l}\text { Mathematic equations } \\
\text { presentation }\end{array}$} & Yes & 7 & $64 \%$ \\
\hline & No & 4 & $36 \%$ \\
\hline \multirow[t]{3}{*}{ User control } & Animation control & 8 & $73 \%$ \\
\hline & Content control & 10 & $91 \%$ \\
\hline & User input & 10 & $91 \%$ \\
\hline \multirow{3}{*}{$\begin{array}{l}\text { Other media besides } \\
\text { animation }\end{array}$} & Haptic & 1 & $9 \%$ \\
\hline & None & 8 & $73 \%$ \\
\hline & Video & 2 & $18 \%$ \\
\hline \multirow[t]{3}{*}{ Experimental design } & One-Group Pretest-Posttest & 1 & $9 \%$ \\
\hline & One-Shot Case Study & 9 & $82 \%$ \\
\hline & Static Group Comparison Design & 1 & $9 \%$ \\
\hline \multirow[t]{3}{*}{ Data collection methods } & Comment content analysis & 4 & $36 \%$ \\
\hline & Performance tests & 2 & $18 \%$ \\
\hline & Questionnaire surveys & 11 & $100 \%$ \\
\hline
\end{tabular}

